\title{
PROPOSTA DE IMPLEMENTAÇÃO DE POLÍTICAS MOTIVACIONAIS PARA REDUÇÃO DA TAXA DE ABSENTEÍSMO: ESTUDO DE CASO NA EMPRESA SABIA COMÉRCIO DE COSMÉTICOS LTDA
}

\section{ARTIGO ORIGINAL}

BATISTA, Mikaele Bianca Duarte ${ }^{1}$, SANTOS, Marcos Vinicius de Souza ${ }^{2}$, BEVILAQUA, Larissa Sampaio ${ }^{3}$, ROBERTO, José Carlos Alves ${ }^{4}$, ALMEIDA, Victor da Silva ${ }^{5}$

BATISTA, Mikaele Bianca Duarte. Et al. Proposta de implementação de políticas motivacionais para redução da taxa de absenteísmo: Estudo de caso na empresa Sabia Comércio de Cosméticos Ltda. Revista Científica Multidisciplinar Núcleo do Conhecimento. Ano 06, Ed. 11, Vol. 12, pp. 190-210. Novembro de 2021. ISSN: 2448-0959, Link de acesso:

https://www.nucleodoconhecimento.com.br/administracao/taxa-deabsenteismo, DOI: 10.32749/nucleodoconhecimento.com.br/administracao/taxa-deabsenteismo

\section{RESUMO}

O presente artigo trata-se de um estudo de caso realizado na empresa Sabia Comércio de Cosméticos LTDA que faz parte do segmento de comércio atacadista de cosméticos. Foi analisado o contexto envolvido nas taxas de absenteísmo presente na organização. Esta taxa é caracterizada pelas faltas crônicas de um funcionário. Quanto maior o grau de absenteísmo, maior será a dificuldade de planejamento do $\mathrm{RH}$, além disso, a perda de dias de trabalho resulta na redução

\footnotetext{
${ }^{1}$ Graduanda do curso de Administração.

${ }^{2}$ Graduando do curso de Administração.

${ }^{3}$ Graduando do curso de Administração.

${ }^{4}$ Orientador. Mestre em Engenharia de produção. Especialista Logística empresarial. Graduado em Administração com Ênfase em Marketing.

${ }^{5}$ Coorientador. Mestre em Engenharia de Processos. Pós-Graduando em Neuropsicopedagogia Institucional. Especialista em Gestão Estratégica de RH. Graduado em Administração e Pedagogia.
}

RC: 101999

Disponível em: https://www.nucleodoconhecimento.com.br/administracao/taxa-deabsenteismo 
da produção e no fracasso em atingir as metas de vendas, o que afeta negativamente os resultados financeiros. Diante disto, este estudo pretende responder: como a implementação de políticas motivacionais podem contribuir com a redução das taxas de absentismo? Diante disso, teve como objetivo geral estabelecer uma proposta de implementação de intervenções, estabelecendo ações que visam reduzir as elevadas taxas de absentismo identificadas na empresa. A metodologia utilizada foi o método aplicado, pesquisa-ação e revisão bibliográfica. Os principais resultados, demostraram que há um elevado grau de absenteísmo na organização e o setor de Recursos Humanos $(\mathrm{RH})$ é a área da empresa com o desempenho funcional mais crítico. Portanto, concluímos que a ferramenta mais adequada para intervenção desse quadro, visando reduzir a alta taxa de absenteísmo, é a utilização de políticas motivacionais. Através da implementação adequada das ações interventivas propostas, haverá a regularização da empresa de forma eficaz.

Palavras-chave: Absenteísmo, plano de intervenção, taxas.

\section{INTRODUÇÃO}

O presente artigo trata-se de um estudo de caso realizado na empresa Sabia Comércio de Cosméticos LTDA, ela faz parte do segmento do segmento de comércio atacadista de cosméticos e produtos de perfumaria volta-se para produtos de higiene pessoal, cosmético, maquiagem, fragrância e outros artigos de beleza., sendo uma Matriz do tipo Sociedade Empresária Limitada, de porte "demais.

Segundo Paiva et al. (2015) o maior grau de absenteísmo dificulta o processo de implantação do planejamento de $\mathrm{RH}$. A perda de dias de trabalho resulta em perda de produção. A escassez de mão de obra leva ao fracasso em atingir as metas de produção, o que pode causar o fracasso em atingir as metas de vendas que afetam negativamente os resultados financeiros. Este trabalho possui o objetivo de estabelecer uma proposta de implementação de medidas de intervenção que 
possam estabelecer ações que reduzam as taxas de absentismo na empresa Sabia Comércio de Cosméticos.

De acordo com Severino (2017) o problema de pesquisa é definido como uma questão fundamentada para realizar uma investigação dentro da temática escolhida. Ela é responsável por fundamentar o desenvolvimento do estudo, pois é através da busca pela resposta que a pesquisa vai sendo direcionada, para tentativa de solucionar a pergunta problema. A questão problema deste artigo é: Como a implementação de políticas motivacionais podem contribuir com a redução das taxas de absentismo?

Com a utilização de metodologia de pesquisa-ação para aprimorar práticas específicas, sendo uma pesquisa baseada na ação, avaliação e análise crítica das práticas com base nos dados coletados, com intuito de introduzir melhorias nas práticas relevantes. Os resultados apresentados nesta pesquisa mostraram que a empresa possui o alto índice da taxa de absenteísmo, sendo o setor de $\mathrm{RH}$ classificado como baixo desempenho na empresa.

Visto isso, espera-se que através das informações apresentados nesse estudo que seja respondido a pergunta problema do artigo e que os objetivos descritos sejam alcançados ao longo da pesquisa. Também se espera que a proposta de intervenção realizada para a empresa seja de acordo com a proposta pela literatura.

\section{FUNDAMENTAÇÃO TEÓRICA}

\subsection{CONCEITO DE ABSENTEÍSMO}

Segundo Balfanz e Byrnes (2013) o absenteísmo é o que acontece quando um funcionário começa a faltar ao trabalho cronicamente. O absenteísmo é caro para os empregadores, chefes e colegas de trabalho e pode custar o trabalho dos infratores reincidentes. Mas, embora o absenteísmo seja frequentemente percebido como um 
problema do funcionário, pesquisas mais recentes revelam que ele também pode ser um sintoma de um problema muito maior com base no empregador.

O absenteísmo é um termo utilizado para se referir a quando um colaborador falta ao serviço de forma não autorizada do funcionário do trabalho. Um funcionário deve ser tratado como ausente para fins dessas estatísticas de absenteísmo, mesmo que ele não compareça ao trabalho após obter permissão prévia (CUCCHIELLA; GASTALDI; RANIERI, 2014).

Para Silva (2013) qualquer funcionário que se apresentar ao serviço, mesmo durante uma parte do dia ou turno, não deve ser contado entre os ausentes. O absentismo voluntário é definido como ausência por causas pessoais do colaborador. Assim sendo, a ausência de trabalhador por motivo de greve, bloqueio ou despedimento, ou seja, ausência involuntária, não é considerada ausência para efeitos destas estatísticas de absentismo.

Segundo Sousa (2013) a taxa de absentismo é a mais baixa do dia de pagamento; aumenta consideravelmente nos dias seguintes ao pagamento dos salários aos bônus. O nível de absenteísmo é comparativamente alto imediatamente após o dia de pagamento; quando os trabalhadores sentem vontade de se divertir ou, em alguns outros casos, voltam para casa, para sua aldeia, para fazer compras para a família ou para encontrá-los.

A porcentagem de absentismo é geralmente mais elevada nos turnos da noite do que nos turnos do dia. Isso ocorre porque os trabalhadores do turno da noite experimentam maior desconforto ou mal-estar no curso de seu trabalho do que durante o dia. 


\subsubsection{MOTIVOS QUE ELEVAM A TAXA DE ABSENTEÍSMO NAS EMPRESAS}

Os três principais fatores que afetam os funcionários e o absenteísmo dos trabalhadores são: fatores organizacionais, fatores sociais e fatores pessoais. Os fatores relacionados à organização podem corresponder a monotonia e a mundanidade do trabalho, pois esses fatores fazem com que o funcionário perca 0 interesse pelo trabalho. Isso o deixa física e mentalmente cansado (CÔBERO; LIMA, 2018).

Segundo Santos e Rodrigues (2020) também pode ser considerado como fator organizacional a pouca importância dada para o absenteísmo, em relação a empresa, causa alta taxa de absenteísmo. A contratação de trabalhador temporário também leva a alto absenteísmo. Assim, as atitudes militantes dos sindicatos também causam alto absenteísmo, pois os trabalhadores ficam frustrados por causa de certas atitudes.

Para Marques e Alonso (2016) a carga de trabalho pesada leva a fadiga excessiva e acidentes industriais. Como a falta de dispositivos de segurança causam baixa moral entre os trabalhadores. A insatisfação leva à aversão ao trabalho e o absenteísmo e a rotatividade tornam-se consequências óbvias. Alguns tipos de supervisores causam desconforto diário relacionados aos procedimentos ou até mesmo fatores interpessoais, causando absenteísmo.

Almeida et al. (2018) apresenta que o excesso de pessoas, fluxo irregular de produção, uso ineficaz de habilidades, treinamento inadequado, sistema de incentivos inadequado, procedimento de reclamação ineficaz, baixo moral e falta de satisfação no trabalho desencadeiam o absenteísmo. Menor salário é uma das razões para o absenteísmo, uma vez que os trabalhadores se ausentam para complementar sua renda trabalhando em outro lugar. 
Quanto aos fatores sociais, o ambiente físico da empresa é inadequado para a prática de trabalho. Causas sazonais, como estação de cultivo, estação de casamento, diversão, festivais religiosos, levam ao absenteísmo. Já em relação aos fatores pessoais a taxa de absentismo é elevada no caso de trabalhadores não qualificados e jovens devido aos seus problemas pessoais. Assim como o complexo de inferioridade, desajustes, insatisfação com o trabalho, negligência por parte de familiares, fazem com que os trabalhadores percam o interesse pelo trabalho e isso desencadeia o absenteísmo (PORTO, 2016).

\subsubsection{O ABSENTEÍSMO A DINÂMICO DE TRABALHO}

Segundo Pereira et al. (2017) o absenteísmo atrapalha toda cadeia de produção. Isso pode causar a paralisação das máquinas e dificultar o fluxo de trabalho suave. Como consequência pode haver a redução na produtividade, assim o custo dos processos tende a aumentar. Isso resulta na redução da margem de lucro da indústria. A taxa de produção e a produtividade continuam baixas. As metas de produção estão alteradas.

Ausência de trabalhadores faz com que o processo fique ocioso. isso resulta na redução do desempenho e da capacidade de outras pessoas ou até mesmo de máquinas. A escassez de mão de obra desencadeada pelo absenteísmo dificulta o fluxograma e a cadeia de processos, causando atrasos e o não alcance de objetivos estabelecidos. Isso os torna vulneráveis a litígios, penalidades e perda de pedidos de clientes (SILVA; SEIBERT; WBATUBA, 2020).

O estudo de Landraf (2016) mostra que os trabalhadores disponíveis precisam estar sobrecarregados e as horas extras precisam ser pagas para completar a tarefa. Isso leva a um maior comprometimento financeiro por parte da empresa. Atrasos na entrega e na execução de pedidos levam à perda de clientes e, portanto, a empresa perde sua reputação. $O$ precioso tempo do empregador é desperdiçado em iniciar uma ação disciplinar contra os ausentes não autorizados. Funcionários ausentes perdem salários. 


\subsubsection{CONSEQUÊNCIAS DO ABSENTEÍSMO PARA EMPRESA}

Segundo a pesquisa de Paiva et al. (2015) o maior grau de absenteísmo dificulta o processo de implantação do planejamento de $\mathrm{RH}$. A perda de dias de trabalho resulta em perda de produção. A escassez de mão de obra leva ao fracasso em atingir as metas de produção, o que, por sua vez, causa o fracasso em atingir as metas de vendas que afetam negativamente os resultados financeiros.

O absenteísmo dificulta o fluxo de trabalho ordenado, isso resulta na redução da margem de lucro da indústria. A taxa de produção e a produtividade continuam baixas. As metas de produção estão alteradas (FUZINATTO; NASCIMENTO; DALBOSCO, 2017).

Como resultado do aumento do custo de produção, o preço de venda da mercadoria deve ser aumentado. Portanto, os clientes têm que acabam tendo opções mais caras dos mesmos serviços. O absenteísmo também influencia na redução da eficiência no trabalho. Também reduz seu interesse no trabalho. Devido ao absenteísmo dos trabalhadores regulares, a indústria tem que depender de funcionários casuais ou abaixo do padrão, o que causa muitos problemas em si, como quebra de maquinário, baixa qualidade de produção, desperdício de matériaprima etc. (SILVA; RODRIGUES, 2014).

Segundo Sousa (2013) como resultado de todos esses fatores, a empresa se torna incapaz de atender integralmente a demanda do mercado e causa atraso no fornecimento aos clientes valiosos. $O$ absenteísmo frequente dos trabalhadores afeta a economia dos trabalhadores também. Isso reduz sua renda. A alta taxa de absenteísmo perturba a política de planejamento de pessoal de uma empresa. $\mathrm{O}$ alto índice de absenteísmo também é motivo de indisciplina entre os trabalhadores. 


\subsection{PERFIL DE COLABORADORES}

De acordo com Ribeiro (2017) os funcionários são os indivíduos contratados por uma pessoa ou empresa para realizar trabalhos para essa pessoa ou empresa, também denominada empregador. Os indivíduos são considerados empregados se o empregador puder controlar o trabalho executado. Os fatores adicionais que tornam alguém um funcionário inclui:

- A pessoa está na folha de pagamento da empresa e recebe um salário ou vencimento específico

- O indivíduo é elegível para benefícios e outras vantagens oferecidas pelo empregador

- Um contrato de trabalho escrito ou implícito

- A pessoa é protegida por lei em termos de salários e direitos trabalhistas

Existem várias classificações de funcionários e as empresas podem contratar um ou vários tipos de funcionários para realizar 0 trabalho. As classificações de funcionários mais comuns incluem:

- Funcionários de meio período

- Funcionários em tempo integral

- Funcionários sazonais

- Funcionários temporários

- Funcionários alugados

Referente aos níveis de funcionários, entre o perfil está o funcionário estável, com sua natureza: Uma pessoa desse tipo ama a segurança em todos os aspectos, sem apetite para o risco. Eles gostam de estabilidade em suas vidas. A identificação desse perfil é na compreensão de aqueles indivíduos que raramente estão em busca de oportunidades em outro lugar, pois eles gostam de um ambiente de trabalho previsível. A melhor maneira de motivá-los é informá-los sobre a lucratividade de uma empresa. Isso Ihes dá esperança de que seu futuro está garantido em uma 
empresa. Eles também gostam da comunicação constante de seu gerente no local de trabalho (MACEDO, 2015).

Segundo Ávila e Stecca (2015) o perfil de colaborador diretor, as pessoas desta natureza adoram ter influência e poder. Eles geralmente aproveitam a oportunidade de liderar projetos e como em sua natureza, a melhor maneira de impulsioná-los é dando-Ihes responsabilidades. Esse senso de responsabilidade se traduz em liderança para eles.

O perfil de colaborador livre é o tipo de funcionário que gosta de trabalhar sozinho, sem supervisão. Eles querem liberdade em sua forma de trabalhar, usam discrição e gostam de controlar o trabalho. Como sugere sua natureza, essas pessoas não gostam de micro gerenciamento. Para motivá-los, deve dar-lhes responsabilidade e confiança em seus esforços. Além disso, qualquer análise rigorosa certamente os desmotivou (TACHIZAWA, 2015).

De acordo com Macedo (2015) os funcionários do tipo temporários são considerados os mais propícios a ter uma taxa de absenteísmo alta, por se tratar de não ter vínculos a longo prazo com a empresa. Quanto ao perfil de funcionário, o tipo de colaborador com mais probabilidade de ter mais faltas é o perfil livre, por ser um tipo de funcionário que não aceita muito bem trabalhar em equipe e nem receber ordens, acaba colaborando para uma alta taxa de absenteísmo.

\subsection{MÉTODOS DE PREVENÇÃO E REVERSÃO DO ABSENTEÍSMO}

Para extrair o melhor dos funcionários no que diz respeito à gestão de desempenho, torna-se essencial manter registros relativos a habilidades de trabalho, educação e certificações, experiência, histórico de carreira etc., para saber quais recursos estão disponíveis para atender aos requisitos de produção / serviço. Esses detalhes capacitam os gerentes de linha a tomar decisões com base em fatos. Esses registros também desempenham um papel importante no planejamento de treinamento e desenvolvimento de carreira para os indivíduos (SILVA, 2014). 
O absenteísmo é provavelmente uma reação humana natural à rotina da vida moderna. A rotina pode ser relaxada ou modificada por meio da concessão de licença remunerada, do encurtamento ou redistribuição dos horários programados, da convivência dos funcionários mais próximos dos locais de trabalho e da adequação das condições físicas da fábrica, principalmente ruído e ventilação.

Segundo Ezaú et al. (2019) a gestão de pessoal deve encorajar a notificação, especialmente nos casos de doença quando é provável que pertença a duração das faltas. Em relação à situação e fatores que envolvem a esfera pessoal e familiar, por exemplo, doença de filhos no caso de mulheres casadas que tornam as ausências inevitáveis, a licença deve ser concedida liberalmente.

Como apresentado por Santos; Borges e Machado (2018) a presença regular pode ser incentivada, até certo ponto, pela oferta de um bônus e outros incentivos pecuniários. Para reduzir o absenteísmo por motivos de doenças, deve-se investir em higiene e segurança industrial. Deve-se notar que nenhuma medida isolada pode ser eficaz no controle do absenteísmo; mas uma combinação hábil de várias medidas certamente levaria aos resultados desejados, podendo ser:

- Fornecimento de condições de trabalho saudáveis e higiênica

- Provisão de Salários e Subsídios Razoáveis e Segurança no Trabalho para Trabalhadores

- Adoção de um procedimento de recrutamento bem definido

- Motivação dos Trabalhadores - Bem-Estar e Medidas Sociais

- Melhor comunicação

- Relações cordiais entre supervisores e trabalhadores

- Desenvolvimento da Educação do Trabalhador 


\section{MATERIAIS E MÉTODOS}

\subsection{PROCEDIMENTOS METODOLÓGICOS}

Segundo Marconi e Lakatos (2017) os procedimentos metodológicos correspondem às etapas de desenvolvimento de um estudo. Ou seja, é de que forma a metodologia de pesquisa será realizada, especificamente no que diz respeito à forma prática de qualquer pesquisa. De acordo com Severino (2017) é também de que modo e sobre como um pesquisador sistematicamente projeta um estudo para garantir resultados válidos e confiáveis que atendam às metas e aos objetivos da pesquisa.

\subsubsection{QUANTO À NATUREZA}

De acordo com Marcondes et al. (2017) a pesquisa aplicada é um tipo de método de pesquisa que visa resolver um problema específico ou fornecer soluções inovadoras para questões que afetam um indivíduo, grupo ou sociedade. Para Severino (2017) é frequentemente referido como um método científico de investigação ou pesquisa contratual porque envolve a aplicação prática de métodos científicos aos problemas do dia a dia. Por isso, esse artigo se caracteriza com natureza aplicada, por se tratar da busca em responder uma pergunta problema elaborada inicialmente.

\subsubsection{QUANTO AOS FINS}

Segundo Severino (2017) a pesquisa-ação é aceita como um método para testar hipóteses em um ambiente do mundo real. Marcondes et al. (2017) descreve que esse método é aplicado para aprimorar práticas específicas, sendo uma pesquisa baseada na ação, avaliação e análise crítica das práticas com base nos dados coletados, a fim de introduzir melhorias nas práticas relevantes. Este tipo de pesquisa é facilitado pela participação e colaboração de vários indivíduos com um propósito comum. Por isso, quantos aos fins, o presente artigo de caracteriza como pesquisa- ação, que entende a pesquisa como um experimento social. 


\subsubsection{QUANTO AOS MEIOS}

Segundo Severino (2017) o meio de pesquisa bibliográfico é definido como qualquer pesquisa que requeira informações a partir de materiais publicados. Lakatos e Marconi (2017) descrevem que esses materiais podem incluir recursos mais tradicionais, como livros, revistas, periódicos, jornais e relatórios, mas também podem consistir em mídia eletrônica, como gravações de áudio e vídeo, filmes e recursos online, como sites, blogs e bancos de dados bibliográficos, desde que sejam publicados de forma oficial. Portanto, os meios utilizados nessa pesquisa são classificados como levantamentos bibliográficos.

\subsection{CARACTERÍSTICAS DA EMPRESA}

A pesquisa foi realizada na empresa SABIÁ DISTRIBUIDORA DE COSMÉTICOS, localizada na Rua Cerina Souto - Galpão 2, no bairro Ponta Negra em Manaus AM. A empresa Sabiá distribuidora de cosméticos LTDA. Faz parte do segmento de comércio atacadista de cosméticos e produtos de perfumaria voltada para produtos de higiene pessoal, cosméticos, maquiagem, fragrância e outros artigos de beleza. A diferença para o comércio varejista é o público consumidor, neste caso mais voltado para empresas e pequenos estabelecimentos (como farmácia, pequenos comércios e salão de cabeleireiro).

A empresa Sabia Comercio de Cosméticos LTDA, é uma empresa sólida que tem como objeto: "comércio varejista e atacadista de cosméticos, farmacêuticos em geral e produtos de perfumaria e de toucador e de essências manipuladas para perfumes e de higiene pessoal, bem como serviços de carga e descarga". Essa empresa é uma MATRIZ do tipo Sociedade Empresária Limitada, de porte "DEMAIS".

\section{RESULTADOS E DISCUSSÃO}

Segundo Severino (2017) o tópico de resultados e discussão é a etapa de um artigo onde o autor apresenta os dados que foram coletados durante o estudo de campo. 
Os resultados correspondem as informações e dados referente ao que foi coletado de forma objetiva no ambiente de pesquisa, já a discussão é o momento em que o autor faz a análise dos resultados que foram coletados, podendo ser realizado a comparação de tudo o que foi avaliado com o que a literatura apresenta sobre a problemática abordada.

\subsection{GRÁFICO DO DESEMPENHO POR ÁREAS DA EMPRESA}

Com a análise realizada na empresa Sabia Comércio de Cosméticos LTDA, foi possível registrar o índice de desempenho funcional de cada setor da empresa. Por se tratar de uma organização de grande porte ela possui setores individuais para cada tipo de atividade interna, como: Setor de Marketing, setor de produção e operações, setor de finanças, setor de administração e setor de logística.

Tendo isso em consideração, os setores mencionados passaram por uma avaliação de seu desempenho, sendo tabulado em gráfico os resultados obtidos, em forma de média por setor, de acordo como apresentado no Gráfico 1.

De acordo com o Gráfico 1 é possível compreender que a área funcional com melhor desempenho é a financeira, com uma média de 4,6, o que mostra que a gestão financeira da empresa é acima da média. No entanto, a área que apresenta menor média no desempenho é a de recursos humanos, o que pode ser um fator para que o desempenho dos colaboradores de todas as áreas possa ser afetado. Visto que esse setor é responsável pela dinâmica e relacionamento entre os funcionários e a empresa. 
Gráfico 1 Resultado obtido da análise do desempenho funcional de cada setor da empresa.

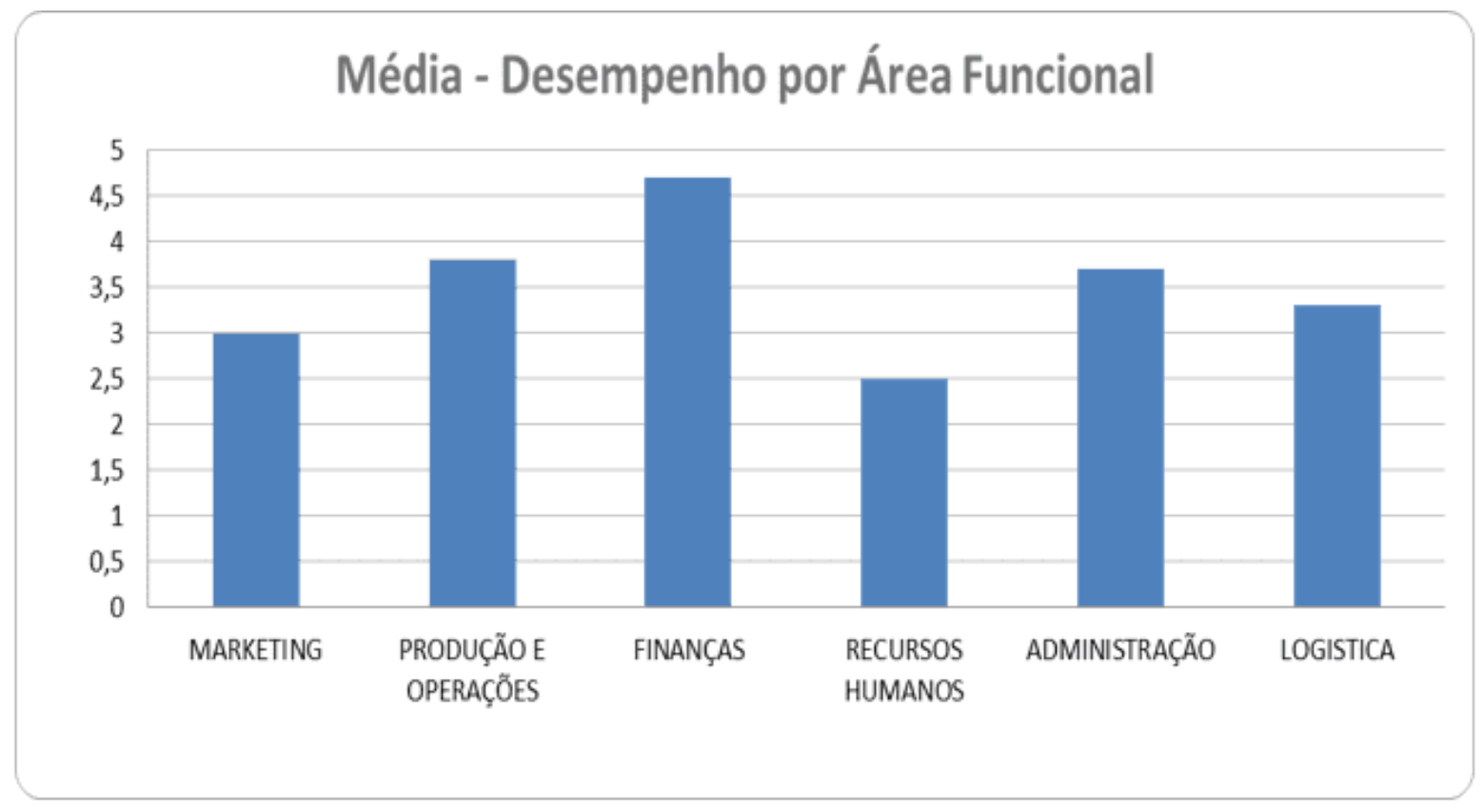

Fonte: Dados obtidos pelos autores, 2021.

\subsection{QUADRO DA ÁREA MAIS CRÍTICA}

O quadro 1 apresenta a área com menor desempenho funcional. $O$ setor de recursos humanos $(\mathrm{RH})$ da empresa Sabia Comércio de Cosméticos apresentou desempenho médio de 2,5, sendo a taxa de absenteísmo, comunicação interna, treinamentos e relação funcionário empresa classificados em grau de avaliação médio. Esses três itens relacionados aos recursos humanos são essenciais para que os colaboradores da empresa, como todo, consigam desempenhar suas funções de forma adequada e que a dinâmica seja ordenada.

Quadro 1 Apresentação do desempenho funcional da área de recursos humanos da empresa.

\begin{tabular}{|l|l|l|}
\hline ÁREA FUNCIONAL & NÍVEL OU GRAU DE AVALIAÇÃO \\
\hline RECURSOS HUMANOS & Ponto Ponto Ponto Ponto Ponto
\end{tabular}

RC: 101999

Disponível em: https://www.nucleodoconhecimento.com.br/administracao/taxa-deabsenteismo 


\begin{tabular}{|c|c|c|c|c|c|c|}
\hline & & $\begin{array}{l}\text { muito } \\
\text { forte } \\
\text { Nota } \\
\text { (5) }\end{array}$ & $\begin{array}{l}\text { forte } \\
\text { Nota } \\
\text { (4) }\end{array}$ & $\begin{array}{l}\text { médio } \\
\text { Nota } \\
\text { (3) }\end{array}$ & $\begin{array}{l}\text { fraco } \\
\text { Nota } \\
(2)\end{array}$ & $\begin{array}{l}\text { muito } \\
\text { fraco } \\
\text { Nota } \\
\text { (1) }\end{array}$ \\
\hline 1 & $\begin{array}{l}\text { A empresa investe em capacitação } \\
\text { para os colaboradores }\end{array}$ & & $\mathrm{X}$ & & & \\
\hline 2 & $\begin{array}{l}\text { Há na empresa benefícios aos } \\
\text { funcionários }\end{array}$ & $\mathrm{x}$ & & & & \\
\hline 3 & Taxa de absenteísmo na empresa. & & & $\mathrm{X}$ & & \\
\hline 4 & $\begin{array}{l}\text { Existe uma comunicação acessível } \\
\text { para sugestões e críticas }\end{array}$ & & & $\mathrm{X}$ & & \\
\hline 5 & $\begin{array}{l}\text { Os colaboradores demonstram } \\
\text { motivação no desempenho de suas } \\
\text { funções }\end{array}$ & & $\mathrm{X}$ & & & \\
\hline 6 & $\begin{array}{l}\text { Há na empresa um programa de } \\
\text { prevenção contra acidentes no local } \\
\text { de trabalho }\end{array}$ & & $\mathrm{X}$ & & & \\
\hline 7 & $\begin{array}{l}\text { A empresa estabelece critérios de } \\
\text { formação profissional para a } \\
\text { contratação }\end{array}$ & & $\mathrm{X}$ & & & \\
\hline 8 & $\begin{array}{l}\text { São feitos treinamentos adequados } \\
\text { de acordo com cada função }\end{array}$ & & & $\mathrm{X}$ & & \\
\hline 9 & $\begin{array}{l}\text { Há uma boa interação entre os } \\
\text { colaboradores na empresa }\end{array}$ & & & $\mathrm{X}$ & & \\
\hline 10 & $\begin{array}{l}\text { A empresa dá o suporte necessário } \\
\text { ao funcionário como benefícios }\end{array}$ & & $\mathrm{x}$ & & & \\
\hline \multicolumn{2}{|c|}{ TOTAL $(\Sigma)$} & 5 & 20 & 0 & 0 & 0 \\
\hline \multicolumn{2}{|r|}{ MÉDIA POR GRAU (POR COLUNA) } & 0,5 & 2 & 0 & 0 & 0 \\
\hline \multicolumn{2}{|c|}{ DESEMPENHO DA ÁREA } & \multicolumn{5}{|l|}{2,5} \\
\hline
\end{tabular}

Fonte: Elaborado pelos autores com base na coleta de dados, 2021

RC: 101999

Disponível em: https://www.nucleodoconhecimento.com.br/administracao/taxa-deabsenteismo 
Esse contexto pode ser explicado pois de acordo com Lacombe (2017) o departamento de $\mathrm{RH}$ desempenha uma ampla variedade de funções e é responsável por ajudar os funcionários a se sentirem seguros, valorizados e devidamente apoiados. A adequada gestão de recursos humanos garante que o departamento de $\mathrm{RH}$ funcione sem problemas e continue a evoluir ao longo do tempo.

Além disso, o setor de $\mathrm{RH}$ também é responsável por desenvolver projetos e programas internos que visam engajar o desempenho funcional dos colaboradores, assim como também é responsável por impulsionar e mediar treinamentos para a capacitação contínua da equipe. Por isso, a falha no desempenho e gestão dos responsáveis por esse setor pode estar diretamente ligada com a Taxa de absenteísmo na empresa.

Pois, segundo o estudo de Sousa (2013) o absenteísmo é a taxa de ausência não planejada no local de trabalho e assim como a rotatividade de funcionários, o absenteísmo é um comportamento negativo no trabalho. Embora certa taxa de absenteísmo seja normal para uma organização, altos níveis de ausência podem indicar problemas na organização.

\subsection{QUADRO DAS AÇÕES INTERVENTIVAS}

Com a análise realizada na empresa foi possível identificar falhas no desempenho da equipe de $\mathrm{RH}$, que podem estar relacionadas a elevada taxa de absenteísmo na empresa. Segundo a pesquisa de Silva e Rodrigues (2014) isso pode afetar o desempenho da equipe, pois quando um colaborador falta ao trabalho com frequência, seu desempenho é prejudicado. Além disso, a produtividade pode ser reduzida, pois com o declínio do desempenho, vem a produtividade necessária na qualidade e na qualidade do trabalho 
Quadro 2 Ações interventivas desenvolvidas para auxiliar na redução do absenteísmo.

\begin{tabular}{|c|c|c|c|c|}
\hline & Ações Interventivas & Cronologia & Duração & Custo \\
\hline 1 & $\begin{array}{l}\text { Implementação da ferramenta de } \\
\text { pesquisas de clima organizacional }\end{array}$ & $\begin{array}{l}\text { Novembro } \\
2021\end{array}$ & 10 dias & $\mathrm{R} \$ 50,00$ \\
\hline 2 & $\begin{array}{l}\text { Desenvolvimento e aplicação de } \\
\text { treinamento para comunicação interna }\end{array}$ & $\begin{array}{l}\text { Dezembro } \\
2021\end{array}$ & 17 dias & $\mathrm{R} \$ 700,00$ \\
\hline 3 & $\begin{array}{l}\text { Implementação do plano } \\
\text { desenvolvimento de carreira }\end{array}$ & $\begin{array}{l}\text { Dezembro } \\
2021\end{array}$ & 20 dias & $\mathrm{R} \$ 600,00$ \\
\hline 4 & $\begin{array}{l}\text { Implementação de programa de } \\
\text { reconhecimento do colaborador }\end{array}$ & Janeiro 2022 & 2 dias & $\mathrm{R} \$ 2.000,00$ \\
\hline 5 & $\begin{array}{l}\text { Implementação de treinamentos de } \\
\text { capacitação profissional }\end{array}$ & $\begin{array}{l}\text { Novembro } \\
2021\end{array}$ & 5 dias & $\mathrm{R} \$ 1.000,00$ \\
\hline \multicolumn{4}{|c|}{ TOTAL } & $R \$ 4.350,00$ \\
\hline
\end{tabular}

Fonte: Elaborado pelos autores com base na coleta de dados, 2021

Portanto, foi desenvolvido um quadro com ações interventivas, para que seja implementado pela empresa o quanto antes e as taxas de ausência no trabalho sejam reduzidas antes de afetar mais a organização, ao ponto de envolver custos e despesas da empresa. Essas ações estão representadas pelo Quadro 2, com a cronologia, duração e custo de cada intervenção.

\subsubsection{IMPLEMENTAÇÃO DA FERRAMENTA DE PESQUISAS DE CLIMA ORGANIZACIONAL}

O clima organizacional pode ser um dos fatores que auxiliam no crescimento da taxa de absenteísmo. Pois, segundo Moreira (2012) o clima organizacional afeta a produtividade, a motivação e o comportamento dos funcionários. Por isso, foi um fator escolhido para que seja dada a adequada atenção, sendo desenvolvimento uma ferramenta de pesquisa para implementação da empresa estudada. 
O quadro 3 representa a estrutura qualitativa dessa implementação, assim como o motivo e método do desenvolvimento e utilização dessa ferramenta de suporte organizacional.

Quadro 3 Planejamento da ferramenta de pesquisa sobre o clima organizacional.

Estrutura da ferramenta de pesquisa de clima organizacional

O quê? Pesquisa de clima organizacional

Por quê? Para a melhor percepção no ambiente de trabalho

Onde? Sabia Comércio de Cosméticos LTDA

Quando? Terceira semana de Novembro de 2021.

Quem? Todos os funcionários da empresa

Como? Através do desenvolvimento de um questionário que possa ser respondido pelos colaboradores com perguntas que envolvam a convivência cotidiana na empresa.

Quanto? R\$50,00

Fonte: Elaborado pelos autores com base na coleta de dados, 2021

A implementação da ferramenta de pesquisas de clima organizacional é uma ação interventiva que pode ser considerada de simples aplicação, por se tratar de um mecanismo que envolve descobrir quais os fatores motivam e desmotivam o funcionário no local de trabalho, para que através das respostas obtidas seja possível traçar metas para a regularização dessas interferências organizacionais.

\subsubsection{IMPLEMENTAÇÃO DE PROGRAMA DE TREINAMENTO PARA COMUNICAÇÃO INTERNA}

Um dos fatores observado na empresa e avaliado com taxa média de desempenho do setor de $\mathrm{RH}$ foi a interação entre os colaboradores na empresa, por isso implantar um treinamento para melhoria na comunicação interna seja um mecanismo adequado para que a taxa de absenteísmo seja reduzida. Pois, de 
acordo com Clemen (2015) a comunicação interna compartilha informações sobre a empresa para que os funcionários possam desempenhar bem seu trabalho. Isso mantém as pessoas informadas.

Portanto, foi escolhida como estratégia para intervenção o treinamento para comunicação interna. A estrutura proposta dessa implementação está apresentada no quadro 4.

Quadro 4 Planejamento programa de treinamento para comunicação interna.

Estrutura programa de treinamento para comunicação interna

O quê? Treinamento de comunicação interna

Por quê? Fornecer um fluxo eficaz de informações entre os departamentos e os colegas de uma organização

Onde? Sabia Comércio de Cosméticos LTDA

Quando? Durante o mês de Dezembro de 2021.

Quem? Todos os funcionários da empresa

Como? Através do plano de comunicação interna, que pode ser repassado através do treinamento, de forma verbal ou virtual.

Quanto? $R \$ 700,00$

Fonte: Elaborado pelos autores com base na coleta de dados, 2021

\subsubsection{IMPLEMENTAÇÃO DO PLANO DE DESENVOLVIMENTO DE CARREIRA}

Um plano de desenvolvimento de carreira pode ser implementado com intuito de motivar o crescimento profissional dos colaboradores, o que pode auxiliar para que a ausência no local de trabalho seja reduzida, dado o incentivo que a empresa pode gerar em cada funcionário. Segundo Pereira (2019) o plano de desenvolvimento de carreira pode ajudar a definir o futuro plano de carreira do colaborador, dando a ele 
a oportunidade de pensar a assumir o próprio progresso, além de ajudar a identificar áreas que precisam de melhorias.

O quadro 5 apresenta a estratégia proposta a ser seguida para implantação de um plano para o desenvolvimento de carreira dos funcionários.

Quadro 5 Estratégia do plano de desenvolvimento de carreira.

Estrutura plano de desenvolvimento de carreira

O quê? Plano de desenvolvimento de carreira

Por quê? Motivação de crescimento profissional

Onde? Sabia Comércio de Cosméticos LTDA

Quando? Durante o mês de Dezembro de 2021.

Quem? Todos os funcionários da empresa

Como? Identificar as habilidades e experiências de que o colaborador precisa para atingir seu objetivo de carreira

Quanto? R\$2.000,00

Fonte: Elaborado pelos autores com base na coleta de dados, 2021

\subsubsection{IMPLEMENTAÇÃO DE TREINAMENTOS DE CAPACITAÇÃO PROFISSIONAL}

A ausência de treinamento contínuo para os funcionários foi identificada na análise da empresa Sabia Comércio de Cosméticos LTDA. O que frequentemente pode estar associado a desmotivação e redução no desempenho organizacional. Pois, de acordo Madruga (2018) os programas de treinamento de funcionários oferecem aos trabalhadores educação e treinamento de habilidades diretamente relacionados ao seu trabalho e isso está diretamente relacionado com a motivação profissional.

Por isso, o quadro 6 apresenta a estratégia que foi proposta para implementação do treinamento profissional contínuo dos colaboradores. 
Quadro 6 Estratégia de treinamentos de capacitação profissional.

Estrutura plano de treinamentos de capacitação profissional

O quê? Treinamentos de capacitação profissional

Por quê? Maior envolvimento, retenção e produtividade dos funcionários

Onde? Sabia Comércio de Cosméticos LTDA

Quando? Durante o mês de Novembro de 2021.

Quem? Todos os funcionários da empresa

Como? Programas de treinamento movidos a energia digital, que introduzem novas possibilidades para o treinamento de funcionários,

Quanto? R\$1.000,00

Fonte: Elaborado pelos autores com base na coleta de dados, 2021

Portanto com a implementação de um treinamento de capacitação profissional os colaboradores podem se sentir valorizados e motivados a realizar as atividades de forma mais eficaz e adequada, para que a empresa possa reconhecê-lo quanto a seu esforço e competência. Isso é importante para reduzir a taxa de absenteísmo na empresa, já que os resultados apresentaram que um dos fatores envolvidos nesse contexto é a desmotivação profissional dos colaboradores.

\section{CONSIDERAÇÕES FINAIS}

No presente artigo foi realizado um estudo de caso realizado na empresa Sabia Comércio de Cosméticos, ela faz parte do segmento do segmento de comércio atacadista de cosméticos e produtos de perfumaria volta-se para produtos de higiene pessoal, cosmético, maquiagem, fragrância e outros artigos de beleza., sendo uma Matriz do tipo Sociedade Empresária Limitada, de porte demais.

Assim, os objetivos estabelecidos foram alcançados através da análise realizado na empresa em questão, sendo avaliado o desempenho funcional de cada setor da empresa e através da tabulação dos resultados foi possível identificar a área com 
menor desempenho e assim elaborar uma proposta de intervenção para que a taxa de absenteísmo reduza e que sejam implementar o programa de forma contínua para que seja prevenido novas elevações. Pois esse aumento, prejudica o desempenho funcional de cada setor e consequentemente afeta a reputação da empresa frente aos clientes.

A pergunta problema desta pesquisa, que consiste na busca da resposta sobre: como a implementação de políticas motivacionais pode contribuir com a redução das taxas de absentismo? Foi respondida com o suporte da análise em estudos científicos acerca das estratégias para prevenir e reduzir o absenteísmo nas empresas, onde foi concluído que a implementação das ferramentas que compõem o planejamento de estratégias de intervenção é o método mais eficaz para redução do absenteísmo na empresa, pois treinamentos de capacitação profissional, implementação de ferramentas de gestão e programas de incentivos são mecanismos que podem motivar o colaborador a permanecer na empresa $e$ executar suas atividades de forma responsável e profissional.

Os resultados obtidos nessa pesquisa mostraram que o setor com menor desempenho é o Recursos Humanos $(\mathrm{RH})$, sendo o alto índice da taxa de absenteísmo um dos motivos para classificação de baixo desempenho dessa área da empresa. Com a pesquisa também foi possível concluir que diversos fatores impulsionam a elevação do absenteísmo. O que faz com que seja necessário a análise geral dos fatores organizacionais que acabam impulsionando a falta no trabalho.

Sendo assim, essa pesquisa, seus resultados e observações não servem apenas para implementação na empresa Sabia Comercio de Cosméticos LTDA, mas também pode servir como direcionamento para que outras organizações possam se conscientizar de que há diversas estratégias que auxiliam para que o absenteísmo diminua. 


\section{REFERÊNCIAS}

ALMEIDA, Marisol Souza et al. OS MOTIVOS DO ABSENTEÍSMO VOLUNTÁRIO E INVOLUNTÁRIO NAS EMPRESAS. In: Vi Congresso De Iniciação Científica Do Ifsp Itapetininga-ISSN 2318-311X. 2018.

ÁVILA, Lucas Veiga; STECCA, Jaime Peixoto. Gestão de pessoas. Santa Maria: Universidade Federal de Santa Maria, Colégio Politécnico, p. 48, 2015.

BALFANZ, Robert; BYRNES, Vaughan. Meeting the challenge of combating chronic absenteeism. Everyone Graduates Center at Johns Hopkins University School of Education, p. 1-2, 2013.

CLEMEN, Paulo. Como implantar uma área de comunicação interna. Mauad Editora Ltda, 2015.

COBÊRO, CLAUDIA; LIMA, CAIO HENRIQUE DE OLIVEIRA. Análise das causas do absenteísmo em uma distribuidora de alimentos. Revista Científica e-Locução, v. 1, n. 14, p. 18-18, 2018.

CUCCHIELLA, Federica; GASTALDI, Massimo; RANIERI, Luigi. Managing absenteeism in the workplace: the case of an Italian multiutility company. ProcediaSocial and Behavioral Sciences, v. 150, p. 1157-1166, 2014.

EZAÚ, João Antonio et al. Proposta para reduzir o alto índice de absenteísmo em uma empresa de alimentos. Brazilian Journal of Business, v. 1, n. 1, p. 2-24, 2019.

FUZINATTO, Andressa Raquel Heinzen; NASCIMENTO, Sabrina; DALBOSCO, Inocencia Boita. Impacto do absenteísmo em uma agroindústria catarinense. Revista Reuna, v. 22, n. 4, p. 89-111, 2017.

LACOMBE, Francisco José Masset. Recursos humanos. Saraiva Educação SA, 2017. 
LANDRAF, Raysa Vieira. Fatores que impactam no absenteísmo dos empregados em dois setores de uma indústria de alimentos-PB. 2016. Trabalho de conclusão de curso.

MACEDO, Ivanildo Izaias. Gestão de pessoas. Editora FGV, 2015.

MADRUGA, Roberto. Treinamento e desenvolvimento com foco em educação corporativa. Saraiva Educação SA, 2018. Trabalho de conclusão de curso.

MARCONDES, Reynaldo Cavalheiro et al. Metodologia para trabalhos práticos e aplicados. São Paulo: Editora Mackenzil, 2017.

MARCONI, Marina; LAKATOS, Eva Maria. Metodologia do trabalho científico. São Paulo: Atlas,2017.

MARQUES, Alonso DN; ALONSO, DIAS. Absenteísmo nas empresas. Brasília: UniCEUB, 2016.

MOREIRA, Elen Gongora. Clima organizacional. IESDE BRASIL SA, 2012.

PAIVA FERREIRA, Bruna Aparecida et al. Influência Do Absenteísmo Nas Relações Trabalhistas. Anais Simpac, v. 4, n. 1, 2015.

PEREIRA DA SILVA, Dorielson et al. O Absenteísmo na Construção Civil: Uma Análise dos Colaboradores em uma Empresa do Sudoeste Baiano. Semana do Administrador do Sudoeste da Bahia-ISSN 2358-6397, v. 3, n. 1, 2017.

PEREIRA, Ana Cecília Resende et al. A contribuição do setor de recursos humanos na capacitação de pessoas em tempos de transformação digital. 2019. Trabalho de conclusão de curso.

PORTO, Ricardo Bersch. ABSENTEÍSMO: causas e consequências na organização. Maiêutica-Estudos Contemporâneos em Gestão Organizacional, v. 4, n. 1, 2016. 
RIBEIRO, Antonio de Lima. Gestão de pessoas. Saraiva Educação SA, 2017.

SANTOS, Danielle Feitosa Barreto; BORGES, Renata Ferreira; MACHADO, Humberto César. Medidas para redução do absenteísmo nas empresas. QUALIA: a ciência em movimento, v. 4, n. 1, p. 77-91, 2018.

SANTOS, JOÃO JOSÉ ANSELMO; RODRIGUES, THAYS PINHEIRO. DIAGNÓSTICO SOBRE ABSENTEÍSMO NAS EMPRESAS DA ZONA COMERCIAL, DO MUNICÍPIO DE ICÓ-CE. Administração de Empresas em Revista, v. 2, n. 20, p. $161-173,2020$.

SEVERINO, Antônio Joaquim. Metodologia do trabalho científico. Cortez editora, 2017.

SILVA, Cláudia Fernanda Trindade; RODRIGUES, Gilmara Ribeiro Santos. Estratégias de controle do absenteísmo no Brasil. Revista Cientefico, v. 14, n. 29 , p. 63-74, 2014.

SILVA, Marcos Marcelino. Absenteísmo: Consequências e impactos na Gestão de Pessoas. Revista especialize on-line IPOG, Goiania, v. 1, n. 7, p. 1-15, 2014.

SILVA, Raiziane Cássia Freire; SEIBERT, Rosane Maria; WBATUBA, Berenice Beatriz Rossner. ABSENTEÍSMO: UM ESTUDO DE CASO COM OS TÉCNICOSADMINISTRATIVOS DE UMA INSTITUIÇÃO DE ENSINO SUPERIOR. Qualitas Revista Eletrônica, v. 19, n. 2, p. 129-149, 2020.

SILVA, VANESSA LEMOS. O problema do absenteísmo no ambiente de trabalho. 2013. Trabalho de conclusão de curso.

SOUSA, Renato. ABSENTEÍSMO E SUA INFLUÊNCIA NAS ORGANIZAÇÕES. ETIC-Encontro De Iniciação Científica-ISSN 21-76-8498, v. 9, n. 9, 2013. 
TACHIZAWA, Takeshy. Gestão com pessoas: uma abordagem aplicada às estratégias de negócios. Editora FGV, 2015.

Enviado: Outubro, 2021.

Aprovado: Novembro, 2021. 